\title{
The relationship between procalcitonin and thyroid autoantibodies in patients with autoimmune thyroiditis
}

\author{
Ali Oncul $^{1,}$ | Ihsan Ates $^{1}$ | Mehmet Fettah Arikan ${ }^{1}$ | Nisbet Yilmaz ${ }^{1}$ | \\ Canan Topcuoglu $^{2}$ | Fatma Meric Yilmaz ${ }^{2}$ | Mustafa Altay ${ }^{1}$
}

${ }^{1}$ Department of Internal Medicine, Ankara Numune Training and Research Hospital, Ankara, Turkey

${ }^{2}$ Department of Biochemistry, Ankara Numune Training and Research Hospital, Ankara, Turkey

\section{Correspondence}

Ali Oncul, Department of Internal Medicine, Ankara Numune Training and Research Hospital, Sıhhiye, Ankara, Turkey.

Email:dr.alioncul@hotmail.com
Background: The aim of this study is to investigate the serum levels of procalcitonin and its association with autoantibodies in patients with euthyroid Hashimoto's thyroiditis.

Methods: A total of 80 participants were included in the study; 40 of which were newly diagnosed with Hashimoto's thyroiditis, aged over 18, and 40 of which were healthy volunteers. The serum levels of procalcitonin were measured by enzymelinked immunosorbent assay kit. Thyroid function tests were analyzed in hormone laboratory with Electro-chemiluminescence immunoassay.

Results: Hashimoto's thyroiditis patients had higher median procalcitonin levels than those of the control group ( $34.3 \mathrm{pg} / \mathrm{mL}$ vs $27.8 \mathrm{pg} / \mathrm{mL}$ respectively; $P=.037$ ). Also, male patients had higher median procalcitonin levels as compared to female patients (37 pg/mL vs $27 \mathrm{pg} / \mathrm{mL}$ respectively; $P=.013$ ). In the Hashimoto's thyroiditis group, procalcitonin level was positively correlated with anti-thyroglobulin and anti-thyroid peroxidase levels ( $r=.559, P<.001 ; r=634, P<.001$, respectively). The procalcitonin and anti-thyroid peroxidase levels were identified to be an independent predictor in diagnosis of Hashimoto's thyroiditis.

Conclusions: The fact that procalcitonin was found to be correlated with thyroid autoantibodies and found to be an independent risk factor for Hashimoto's thyroiditis in the regression analysis in the framework of this study urges us to think that procalcitonin may be associated with the autoimmunity.

KEYWORDS

autoimmunity, calcitonin, chronic lymphocytic thyroiditis, pre-procalcitonin

\section{1 | INTRODUCTION}

Hashimoto thyroiditis (HT) is a chronic inflammatory disease characterized by destruction of thyroid follicles resulting in infiltration of $\mathrm{T}$ and B lymphocytes histopathologically. The B-lymphocytes produce thyroid autoantibodies through plasma cells when they are activated by antigens, resulting in damage to thyroid tissue. ${ }^{1,2}$ T-lymphocytes play a role in the pathogenesis of HT and Th1 and Th2 lymphocytes that are formed by differentiation of CD 4 T helper lymphocytes. ${ }^{3}$ Th1 lymphocytes act in two different ways by synthesizing pro-inflammatory cytokines (IL-2, IFN-g, TNF, IL-1b, IL 12...). In the first one, they stimulate the CD 8 cytotoxic T cells, which leads to apoptotic destruction of thyroid cells, ${ }^{4,5}$ and in the second one, these cytokines activate the macrophages, leading to direct destruction of thyrocytes. ${ }^{6,7}$ Th2 lymphocytes synthesize IL- 4 and IL- 5 when they are stimulated by antigens ${ }^{8}$ and cause production of thyroid autoantibodies, ${ }^{4}$ and destruction of follicles in thyroid as a result.

The cytokines (IL-2, IL-4, IL-5, IL-6, IFN- $\gamma$, TNF- $\alpha$, IL-1b, IL 12...), which are produced by stimulated $\mathrm{T}$ cells after antigens provoke the immune system, cause damage to the thyrocytes through a variety 
of mechanisms as well as increase in several acute phase reactants, (Erythrocyte sedimentation rate, C-reactive protein, serum amyloid $\mathrm{A}$ and fibrinogen) ${ }^{9}$ which are associated or non-associated with autoimmunity.

Similarly, another recently discovered acute phase reactant, which is also associated with some autoimmune diseases, is procalcitonin (PCT) ${ }^{10-12}$ PCT, first discovered by Moya et al. in $1975,{ }^{13}$ is a peptide precursor of the hormone calcitonin. It is produced by the pulmonary and intestinal neuroendocrine cells and the parafollicular cells in thyroid. It is comprised of 116 amino acids and weighs $13 \mathrm{kDa} .{ }^{14}$ PCT is frequently an increased acute phase reactant in the bacterial infection-related inflammation, ${ }^{15,16}$ and it is reported that its serum level increases in some autoimmune diseases. ${ }^{10-12}$ Nevertheless, its relation with $\mathrm{HT}$, an autoimmune disease with a chronic inflammation, is still unknown. Our objective here is to investigate the serum levels of PCT and its association with autoantibodies in patients with euthyroid HT.

\section{MATERIAL AND METHODS}

\section{1 | Study population}

This study was performed as a dissertation study in the Internal Medicine Clinic of Ankara Numune Training and Research Hospital, between December 2015 and March 2016. The study was conducted in accordance with the Declaration of Helsinki and approved by the Local Ethics Research Committee for human studies. All subjects provided a written informed consent prior to participation in the study.

A total of 80 participants, 40 of whom have newly been diagnosed with euthyroid and remaining 40 patients who were healthy volunteers without a known disease aged over 18, were included in the study. The patients, who had thyroid medullary carcinoma, small cell lung carcinoma, acute-chronic renal disease, liver disease, severe surgical intervention, empirical use of antibiotics, bacterial infection in the lung or in the other organs, were excluded from the study. The diagnosis of HT was established by anti-thyroglobulin (anti-TG) in serum and/or increased levels of anti-thyroid peroxidase (anti-TPO) and/or the presence of heterogeneous echogenicity in thyroid parenchyma revealed by thyroid ultrasonography (USG). Of the patients diagnosed with $\mathrm{HT}$, euthyroid patients with normal levels of thyroid stimulating hormone (TSH) and free thyroxine (fT4) were included in the study. The control group included patients with normal serum TSH, fT4, anti-TG and anti-TPO measurements and patients eliminated with HT after thyroid USG.

Blood pressure measurement was performed as indicated in 2013 ESH/ESC Arterial Hypertension Guidelines at the initial examination of the participants of the study. ${ }^{17}$ Omron M3 blood pressure monitor, calibrated according to ESH-IP (European Society of Hypertension International Protocol) 2002 and 2010, was used for blood pressure measurements. ${ }^{18}$

The body mass index (BMI) was calculated by dividing the body weight $(\mathrm{kg})$ into the square of height in meters $\left(B M I=\mathrm{kg} / \mathrm{m}^{2}\right)$.

\section{2 | Biochemical parameters}

Blood samples were collected in the morning after the 8 hours fasting for biochemical parameters. Samples were quickly centrifuged at $2500 \mathrm{~g}$ for 10 minutes to separate the plasma and serum, and serum samples were kept at $-80^{\circ} \mathrm{C}$. Then all parameters were measured in the same serum sample at once.

The TSH, fT4, anti-TPO and anti-TG were measured with a Cobas e 601 (Catalogue No: 06368697190, Roche Diagnostics, Mannhaim, Germany) autoanalyzer using the electrochemyluminescence immunoassay method.

C-reactive protein (CRP) was measured by immunoturbidimetric method using Hitachi Modular P800 (Roche Diagnostics Corp., Indianapolis, Indiana, USA) analyzer. The serum levels of PCT were measured by ELISA kit (BioVendor R\&D, Human procalcitonin ELISA, Cat. No.: RD191006200R). The results were expressed in pg/mL.

\section{3 | Statistical analysis}

Statistical Package for Social Sciences (SPSS) for Windows 20 (IBM SPSS Inc., Chicago, IL) was used for statistical analyses. Normal distribution of data was evaluated with Kolmogorov-Smirnov test. Numeric variables with normal distribution were presented in mean \pm standard deviation and numeric variables without normal distribution were presented in median. Categorical variables were presented in figures and percentage. The correlation between numerical parameters was examined with Spearman correlation analysis. $T$ test (for numeric variables with normal distribution) and Mann-Whitney $U$ Test (for numeric variables without normal distribution) were used to identify the risk factors, which differed in two groups, in independent samples. Chi-squareTest and Fisher's Final Chi-square Test were used to compare the categorical data. The effects of risk factors associated with HT were analyzed by univariable logistic regression analysis. The independent predictors were identified by stepwise multivariate logistic regression model that included significant risk factors from univariable logistic regression analysis. $A P<.05$ value was considered significant in statistical analyses.

\section{3 | RESULTS}

80 patients in total, consisting of $40 \mathrm{HT}$ patients (6 males, 34 females, mean age: $32.80 \pm 10.4$ years) and 40 healthy control group participants, ( 9 males, 31 females, mean age: $32.60 \pm 10.9$ years) were included in the study. Both of the groups had similar demographical characteristics such as age, BMI, gender, and systolic blood pressure (Table 1). No smoker participants were detected among the study population. The HT group had higher diastolic blood pressure (65.45 $\pm 9.1 \mathrm{~mm} \mathrm{Hg}$ vs $58.08 \pm 10.5 \mathrm{~mm} \mathrm{Hg}$ respectively; $P<.05$ ), antiTG and anti-TPO levels than those of the control group as presented in Table 1. Mean systolic and diastolic blood pressure of male patients in HT group (systolic: $130.7 \pm 9.3$ vs $119.6 \pm 8.7 ; P=.008$, diastolic: $77.7 \pm 9.8$ vs $63.3 \pm 8.7 ; P<.001$, respectively) were determined higher in comparison with female patients. 
TABLE 1 The demographic charesteristics and laboratory findings of study population

\begin{tabular}{|c|c|c|c|}
\hline Variables & $\begin{array}{l}\text { Euthyroid } \\
(n=40)\end{array}$ & $\begin{array}{l}\text { Control } \\
(n=40)\end{array}$ & $P$ \\
\hline $\begin{array}{l}\text { Gender(male), } \\
\mathrm{n}(\%)\end{array}$ & $6(15.0)$ & $9(22.5)$ & .568 \\
\hline Age (years) & $32.80 \pm 10.4$ & $32.60 \pm 10.9$ & .933 \\
\hline $\mathrm{BMI}\left(\mathrm{kg} / \mathrm{m}^{2}\right)$ & $25.61 \pm 5.3$ & $26.10 \pm 4.1$ & .647 \\
\hline $\begin{array}{l}\text { Systolic BP } \\
\text { (mm Hg) }\end{array}$ & $121.30 \pm 9.6$ & $117.78 \pm 12.6$ & .164 \\
\hline $\begin{array}{l}\text { Diastolic BP } \\
(\mathrm{mm} \mathrm{Hg})\end{array}$ & $65.45 \pm 9.1$ & $58.08 \pm 10.5$ & $<.001^{*}$ \\
\hline $\mathrm{TSH}(\mu \mathrm{IU} / \mathrm{mL})$ & $2.1(0.66-4.46)$ & $1.82(0.5-3.6)$ & .149 \\
\hline FT 4 (ng/dL) & $1.17 \pm 0.1$ & $1.15 \pm 0.1$ & .583 \\
\hline $\begin{array}{l}\text { Anti-TG } \\
(I U / m L)\end{array}$ & 175.7 (16.68-1538) & $12(4-95.19)$ & $<.001^{*}$ \\
\hline Anti-TPO (IU/mL) & $54.57(5-1000)$ & $6.53(2-20.6)$ & $<.001^{*}$ \\
\hline $\begin{array}{l}\text { Procalcitonin } \\
\text { Level }(\mathrm{pg} / \mathrm{mL})\end{array}$ & $34.3(15.7-90.0)$ & $27.8(10-72.86)$ & $.037^{*}$ \\
\hline $\mathrm{CRP}(\mathrm{mg} / \mathrm{L})$ & $1.16(0.15-12.0)$ & $1.24(0.17-7.17)$ & .881 \\
\hline
\end{tabular}

$\mathrm{BP}$, blood pressure; BMI, body mass index; TSH, thyroid stimulating hormone; fT4, free thyroxine; anti-TG, anti thyroglobulin; anti-TPO, antithyroid peroxidase; CRP, C-reactive protein.

Continuous variables are expressed as mean \pm SD or median (min-max).

Categorical variables are expressed as $\mathrm{n}(\%)$. ${ }^{*} P<.05$.

HT patients had higher median PCT levels than those of the control group (34.3 pg/mL vs $27.8 \mathrm{pg} / \mathrm{mL}$, respectively; $P=.037$ ) (Figure 1 ). Also, male patients had higher median PCT levels as compared to female patients ( $37 \mathrm{pg} / \mathrm{mL}$ vs $27 \mathrm{pg} / \mathrm{mL}$, respectively; $P=.013$ ).

A positive correlation existed between PCT level and systolic and diastolic blood pressures in the entire population and HT group
(The entire population; $r=.320, P=.004 ; r=-.267, P=.017 ; \mathrm{HT} ; r=.355$, $P=.025 ; r=.420, P=.007$ respectively). For the HT group, $P C T$ level was positively correlated with anti-TG and anti-TPO levels $(r=.559, P<.001$; $r=634, P<.001$, respectively) (Figure 1 ). No correlation was identified between the PCT levels with anti-TG and anti-TPO levels in the entire population and control group (Table 2).

The PCT and anti-TPO levels were identified to be an independent predictor in diagnosis of $\mathrm{HT}$, in the multivariate logistic regression model including gender, diastolic blood pressure, PCT, anti-TG and anti-TPO risk factors that were found to be associated with HT.

An increase in one unit in the PCT level increased the risk for HT by 1.478 times and an increase in one unit in the anti-TPO level increased the risk for HT by 1.164 times considering the other risk factors unchanged (Table 3).

\section{4 | DISCUSSION}

In our study, we detected that the serum level of PCT was higher in the HT group than that of the healthy control group. PCT level was positively correlated with anti-TG and anti-TPO levels in HT group. Furthermore, PCT was identified to be an independent predictor in the diagnosis of HT as anti-TPO in the multivariate logistic regression model. To the best of our knowledge, this study is the first to investigate the relationship of serum PCT level with autoimmunity in patients with HT.

After a long time of its discovery, procalcitonin was indicated to be an increasing marker in the bacterial infections by Assicot et al. ${ }^{14}$ The increased level of PCT in bacterial infections is suggested to have occurred through bacterial endotoxins and cytokines. ${ }^{16}$ However, PCT's relationship with a variety of diseases has been investigated by many researchers since its role and physiology in the organism is not clearly
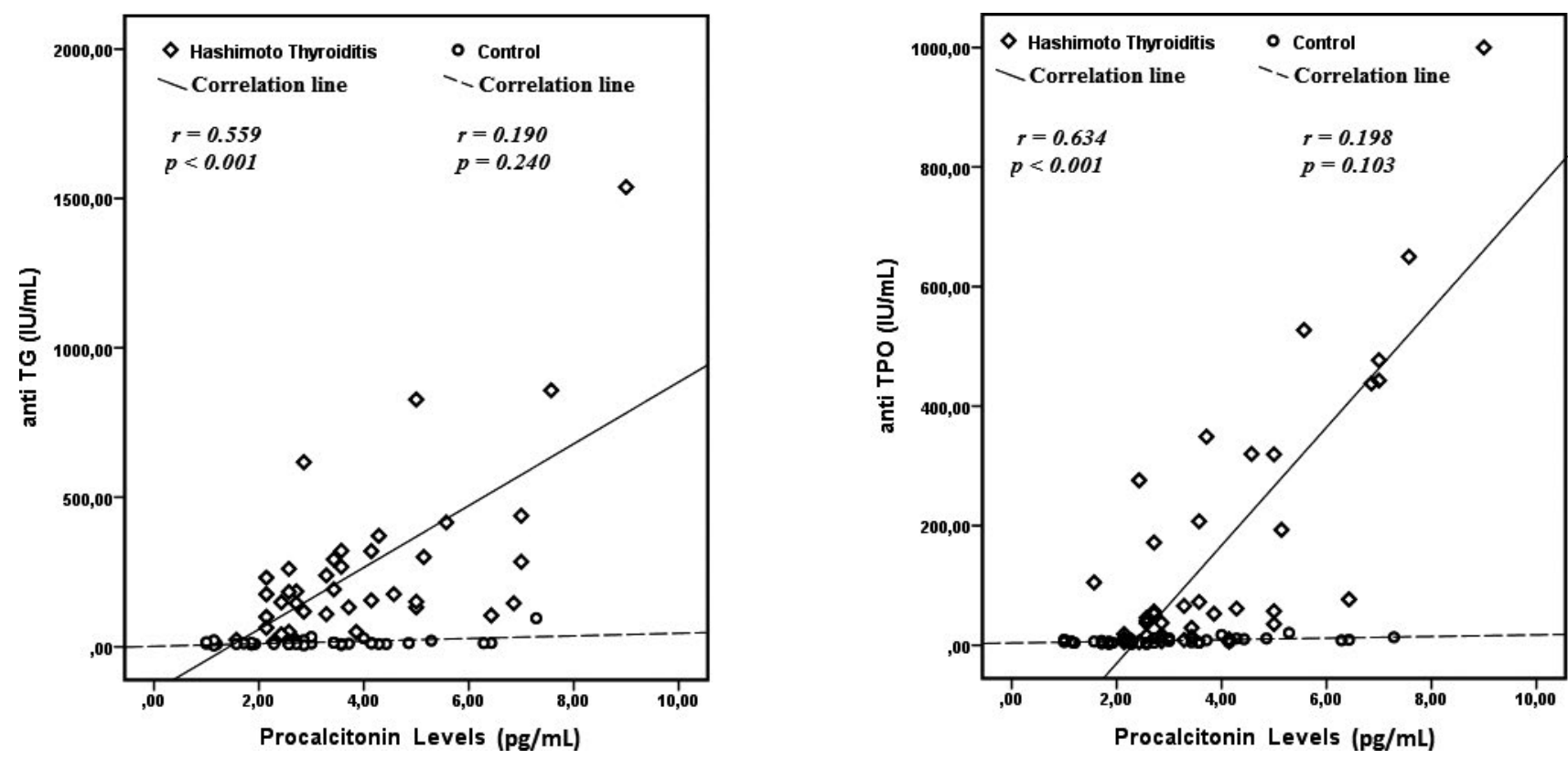

FIGURE 1 Correlation analysis between procalcitonin and thyroid autoantibodies 


\begin{tabular}{|c|c|c|c|c|c|c|}
\hline \multirow[b]{2}{*}{ Variables } & \multicolumn{2}{|c|}{ All population } & \multicolumn{2}{|c|}{ Control } & \multicolumn{2}{|c|}{ Hashimoto thyroiditis } \\
\hline & $r$ & $P$ & $r$ & $P$ & $r$ & $P$ \\
\hline Age & .152 & .179 & .038 & .817 & .254 & .114 \\
\hline Systolic BP & .320 & $.004^{*}$ & .287 & .072 & .355 & $.025^{*}$ \\
\hline Diastolic BP & .267 & $.017^{*}$ & .075 & .646 & .420 & $.007^{*}$ \\
\hline BMI & .069 & .542 & .152 & .350 & .083 & .609 \\
\hline TSH & .151 & .181 & .102 & .533 & .098 & .547 \\
\hline FT 4 & .161 & .119 & .154 & .103 & .104 & .523 \\
\hline Anti-TG & .404 & $<.001^{*}$ & .190 & .240 & .559 & $<.001^{*}$ \\
\hline Anti-TPO & .532 & $<.001^{*}$ & .198 & .103 & .634 & $<.001^{*}$ \\
\hline CRP & .146 & .196 & .047 & .773 & .244 & .130 \\
\hline
\end{tabular}

TABLE 2 Clinics and laboratory parameters associated with procalcitonin level

BP, blood pressure; BMI, body mass index; TSH, thyroid stimulating hormone; fT4, free thyroxine; anti TG, anti thyroglobulin; anti TPO, anti-thyroid peroxidase; CRP, C-reactive protein.

$r=$ Spearman's rank correlation coefficient.

${ }^{*} P<.05$.

\begin{tabular}{|c|c|c|c|c|}
\hline \multirow[b]{2}{*}{ Variables } & \multicolumn{2}{|l|}{ Univariable } & \multicolumn{2}{|l|}{ Multivariable } \\
\hline & OR $(95 \% \mathrm{Cl})$ & $P$ & OR $(95 \% \mathrm{Cl})$ & $P$ \\
\hline Diastolic BP & $1.084(1.027-1.143)$ & $.003^{*}$ & - & - \\
\hline Procalcitonin & $1.389(1.033-1.869)$ & $.030^{*}$ & $1.478(1.075-2.239)$ & $.035^{*}$ \\
\hline Anti-TG & $1.069(1.023-1.117)$ & $.003^{*}$ & - & - \\
\hline Anti-TPO & $1.160(1.052-1.278)$ & $.003^{*}$ & $1.164(1.052-1.289)$ & $.003^{*}$ \\
\hline
\end{tabular}

TABLE 3 Determination of parameters predicting the risk for hypothyroidism with logistic regression analysis

$\mathrm{BP}$, blood pressure; anti TG, anti thyroglobulin; anti TPO, anti-thyroid peroxidase.

Nagelkerke $\mathrm{R}^{2}=.55, P<.05 .{ }^{*} \mathrm{P}<.05$.

known. For example, the level of PCT was reported to have elevated in severe traumas, surgical procedures, ${ }^{19}$ and medullar thyroid cancer. ${ }^{20}$

In autoimmune diseases that are an inflammatory case, it was reported that PCT level increased in some diseases during activation state whereas it increased in some diseases only during the infection state. The PCT level was normal in systemic lupus erythematosus, rheumatoid arthritis, ${ }^{21}$ giant cell arteritis, ${ }^{22}$ and antineutrophil cytoplasmic antibody associated systemic vasculitis, ${ }^{23}$ and higher in Wegener's granulomatosis, microscopic polyangiitis, ${ }^{21}$ Kawazaki, ${ }^{11}$ Good pasture syndrome, ${ }^{12}$ and adult onset still's disease. ${ }^{24}$ The authors suggest that increased PCT level in Wegener's granulomatosis and Good pasture syndrome is related to release of PCT into the blood from tissues injured by destruction of the organs (the kidneys and lungs) that are often involved in these diseases. ${ }^{12}$ A study supporting this suggestion was performed by Nylen et al. who observed the release of PCT from pulmonary neuroendocrine cells in patients with inhalation injury. ${ }^{25}$

In our study, the patients with euthyroid HT had higher serum levels of PCT and were higher than those of the healthy control group. There is no study in the literature investigating the relationship between the HT and PCT. There might be several possible causes why we identified the PCT level to be higher.

As specified by Nylen et al. the first of these might be release of PCT into the blood as a result of the destruction of the tissues in which PCT is synthesized. PCT, synthesized in the parafollicular C cells of thyroid, might have been released as a result of tissue damage depending on the destruction of thyroid follicles after a chronic inflammation in $\mathrm{HT}$, and the serum levels might have been elevated as a consequence. ${ }^{25}$ The second possible cause might be calcitonin I (CALC-1) gene, that enables production of PCT-calcitonin through the cytokines (IL-2, IL-4, IL-5, IL-6, IFN-g, TNF- $\alpha$, IL-1b, IL 12...) synthesized by lymphocytes that play a role in the pathogenesis of HT. The signal required to increase the CALC-1 gene expression still remains unknown, and a possible signal is suggested to be directly through toxins or indirectly through humoral and cellular immune system. ${ }^{26}$

Another cause might be that the calcitonin level was high in several studies on benign thyroid diseases (Reactive C-cell hyperplasia in neonates, HT, autoimmune thyroiditis, and follicular thyroid adenoma), ${ }^{20,27}$ although its cause was not clearly explained; it suggests that $\mathrm{PCT}$, a precursor of calcitonin, might be higher in these diseases.

Despite the lack of data on PCT levels differing by gender in autoimmune diseases, a study on patients with metabolic syndrome reported higher PCT levels in males as compared to the females. Furthermore, patients with higher PCT levels were old and overweight people. It was stated that this was related to the BMI level and mean age of males were higher than women. ${ }^{28}$ However, in our study a significant difference was not determined for $\mathrm{BMI}$ and age of males in comparison with females. For this reason, it should be considered that there might be other metabolic syndrome parameters with an exception of age and BMI level which can affect PCT levels. For instance, in our study systolic and diastolic blood pressure of the male patients in HT group was determined higher in comparison to females. And in correlation analysis, a positive correlation between blood pressures and PCT was determined. 
In this case, we can deduce that PCT level of the male patients in HT group is higher in comparison with females due to their blood pressure.

The correlation found in our study between the PCT levels and the systolic and diastolic blood pressures in the entire population and HT group might be related to the effects of chronic inflammation on the vascular structure. Increased PCT level in a study by Mallamaciet et al. on patients with hypertension is consistent with our dissertation. ${ }^{29}$

Moreover, normal levels of CRP in both of the groups eliminate the risk for a possible bacterial infection for which we were unable to identify a focus.

There are no statistical studies that PCT could predict the autoimmunity in the autoimmune diseases where PCT levels are high. In the present study, PCT level was identified to be an independent predictor of HT as anti-TPO, which is an autoantibody that diagnoses HT.

The major limitations of this study include cross-sectional design, limited number of patients, inadequate number of males, and studying PCT levels only on patients with euthyroid HT.

As a result, we observed that the patients with $\mathrm{HT}$ had higher levels of PCT as compared to the healthy control group. PCT being the independent predictor of $\mathrm{HT}$, as indicated in the multivariate regression analysis, suggests that PCT could be a hormone associated with the autoimmunity. Extensive and further researches are needed in this regard.

\section{ACKNOWLEDGMENTS}

None.

\section{REFERENCES}

1. Chiovato L, Bassi P, Santini F, et al. Antibodies producing complementmediated thyroid cytotoxicity in patients with atrophic or goitrous autoimmune thyroiditis. J Clin Endocrinol Metab. 1993;77:1700-1705.

2. Ates I, Altay M, Yilmaz FM, et al. The impact of levothyroxine sodium treatment on oxidative stress in Hashimoto's thyroiditis. Eur $J$ Endocrinol 2016;174:727-734.

3. Berger A. Th1 and Th2 responses: what are they? BMJ. 2000;321:424

4. Liblau RS, Singer SM, McDevitt HO. Th1 and Th2 CD4+ T cells in the pathogenesis of organ-specific autoimmune diseases. Immunol Today. 1995;16:34-38.

5. Altay M, Ates I, Yilmaz FM, Topcuoglu C, Kaplan M. The role of circulating s TWEAK in the pathogenesis of Hashimoto's thyroiditis and its relationship with other cytokines - a pilot study. Endokrynol Pol 2016.

6. Weetman AP. Cellular immune responses in autoimmune thyroid disease. Clin Endocrinol. 2004;61:405-413.

7. Weetman AP. Autoimmune thyroid disease. Autoimmunity. 2004;37: 337-340.

8. Grubeck-Loebenstein B, Buchan G, Chantry D, et al. Analysis of intrathyroidal cytokine production in thyroid autoimmune disease: thyroid follicular cells produce interleukin-1 alpha and interleukin-6. Clin Exp Immunol. 1989;77:324-330.

9. Erden S, Buyukozturk S, Vural P, Degirmencioglu S. Acutephase reactans in Hashimoto thyroiditis. Int Immunopharmacol. 2008;8:1863-1865.

10. Zycinska K, Wardyn KA, Zielonka TM, Tyszko P, Straburzynski M. Procalcitonin as an indicator of systemic response to infection in active pulmonary Wegener's granulomacytosis. J Physiol Pharmacol. 2008;59(Suppl 6):839-844.
11. Okada Y, Minakami H, Tomomasa T, et al. Serum procalcitonin concentration in patients with Kawasaki disease. J Infect. 2004;48:199-205.

12. Morath C, Sis J, Haensch GM, Zeier M, Andrassy K, Schwenger V. Procalcitonin as marker of infection in patients with Goodpasture's syndrome is misleading. Nephrol Dial Transplant. 2007;22:2701-2704.

13. Moya F, Nieto A, R-Candela JL. Calcitonin biosynthesis: evidence for a precursor. Eur J Biochem 1975;55:407-413.

14. Assicot M, Gendrel D, Carsin H, Raymond J, Guilbaud J, Bohuon C. High serum procalcitonin concentrations in patients with sepsis and infection. Lancet. 1993;341:515-518.

15. Gendrel D, Bohuon C. Procalcitonin, a marker of bacterial infection. Infection. 1997;25:133-134.

16. Dandona P, Nix D, Wilson MF, et al. Procalcitonin increase after endotoxin injection in normal subjects. J Clin Endocrinol Metab. 1994;79:1605-1608.

17. Mancia G, Fagard R, Narkiewicz K, et al. 2013 ESH/ESC guidelines for the management of arterial hypertension: the Task Force for the Management of Arterial Hypertension of the European Society of Hypertension (ESH) and of the European Society of Cardiology (ESC). Eur Heart J. 2013;34:2159-2219.

18. O'Brien E, Atkins N, Stergiou G, et al. European Society of Hypertension International Protocol revision 2010 for the validation of blood pressure measuring devices in adults. Blood Press Monit. 2010;15:23-38.

19. Uzzan B, Cohen R, Nicolas P, Cucherat M, Perret GY. Procalcitonin as a diagnostic test for sepsis in critically ill adults and after surgery or trauma: a systematic review and meta-analysis. Crit Care Med. 2006;34:1996-2003.

20. Kaczka K, Mikosinski S, Fendler W, Celnik A, Pomorski L. Calcitonin and procalcitonin in patients with medullary thyroid cancer or bacterial infection. Adv Clin Exp Med. 2012;21:169-178.

21. Schwenger V, Sis J, Breitbart A, Andrassy K. CRP levels in autoimmune disease can be specified by measurement of procalcitonin. Infection. 1998;26:274-276.

22. Schmidt J, Duhaut P, Bourgeois AM, et al. Procalcitonin at the onset of giant cell arteritis and polymyalgia rheumatica: the GRACG prospective study. Rheumatology. 2009;48:158-159.

23. Espinosa-Morales R, Escalante A. Use of procalcitonin as a diagnostic test: comment on the article by Eberhard et al.. Arthritis Rheum 1998;41:567-568.

24. Chen DY, Chen YM, Ho WL, Chen HH, Shen GH, Lan JL. Diagnostic value of procalcitonin for differentiation between bacterial infection and non-infectious inflammation in febrile patients with active adultonset Still's disease. Ann Rheum Dis. 2009;68:1074-1075.

25. Nylen ES, O'Neill W, Jordan MH, et al. Serum procalcitonin as an index of inhalation injury in burns. Horm Metab Res 1992;24:439-443.

26. Buhaescu I, Yood RA, Izzedine H. Serum procalcitonin in systemic autoimmune diseases-where are we now? Semin Arthritis Rheum. 2010;40:176-183.

27. Verga U, Ferrero S, Vicentini L, et al. Histopathological and molecular studies in patients with goiter and hypercalcitoninemia: reactive or neoplastic C-cell hyperplasia? Endocr Relat Cancer. 2007;14:393-403.

28. Abbasi A, Corpeleijn E, Postmus D, et al. Plasma procalcitonin is associated with obesity, insulin resistance, and the metabolic syndrome. J Clin Endocrinol Metab. 2010;95:E26-E31.

29. Mallamaci F, Leonardis D, Pizzini P, Cutrupi S, Tripepi G, Zoccali C. Procalcitonin and the inflammatory response to salt in essential hypertension: a randomized cross-over clinical trial. J Hypertens 2013;31: 1424-1430. discussion 1430

How to cite this article: Oncul A, Ates I, Arikan MF, Yilmaz Nisbet, Topcuoglu C, Yilmaz FM, and Altay M. The relationship between procalcitonin and thyroid autoantibodies in patients with autoimmune thyroiditis. J Clin Lab Anal. 2017;31:e22123. https://doi.org/10.1002/jcla.22123 